\title{
Immune dysfunction in chronic kidney disease
}

\author{
Sara Cardoso Fernandes ${ }^{1}$ iD, Ana Carina Ferreira ${ }^{1,2}$ iD \\ ${ }^{1}$ Nephrology Department, Hospital Curry Cabral, Centro Hospitalar Universitário Lisboa Central, Lisbon, Portugal \\ 2 Nova Medical School, Lisbon, Portugal
}

\section{ABSTRACT}

Chronic kidney disease is characterized by immune dysfunction that increases predisposition to infections, virus-associated cancers and impaired response to vaccination. The altered immune response is caused by impairment of both innate and adaptive immune systems, as well as other factors that are hallmarks of renal disease, such as uremia, malnutrition, chronic inflammation, mineral bone disease and anemia. The aim of this article is to review the causes and mechanisms that lead to immune dysfunction in patients with chronic kidney disease.

Key-words: Immune dysfunction, chronic kidney disease, uremia

C 2021 Portuguese Journal of Nephrology \& Hypertension. Published by Publicações Ciência \& Vida This is an open access article under the CC BY-NC-ND license (http://creativecommons.org/licenses/by-nc-nd/4.0/).

\section{INTRODUCTION}

Chronic kidney disease (CKD) is a prevalent disease associated with increased risk of mortality and cardiovascular morbidity. ${ }^{1} \mathrm{~A}$ study published in 2004, with a cohort of 1,120,295 adults, demonstrated an increased risk of death, cardiovascular events and hospitalization in association with an estimated glomerular filtration rate (GFR) of less than $60 \mathrm{ml} / \mathrm{min} / 1.73 \mathrm{~m}^{2}$. The adjusted hazard ratio (HR) increased from 1.2 (for CKD stage 3a) to 5.9 (for CKD stage 5), excluding renal transplanted patients and dialysis patients.

In addition to cardiovascular disease, infections are an important cause of mortality, constituting the second most common cause of death among patients with end-stage renal disease (ESRD). Powe et al showed that sepsis is a frequent event in patients on hemodialysis (HD) or peritoneal dialysis (PD), occurring in $10 \%$ of patients over a 7 years follow-up period ${ }^{3}$. Also, mortality risk due to sepsis is about 100 to 300 -fold higher in dialysis patients than the general population $^{4}$

This increased risk of infection is due to an immune dysfunction that affects both the innate and adaptive immune systems of CKD patients, leading to a state of both immune activation and immunosuppression. It occurs irrespective of the underlying disease and confers an increased predisposition to infections, virus-associated cancers and impaired response to vaccination ${ }^{5}$. Uremia, malnutrition, chronic inflammation, vitamin $\mathrm{D}$ deficiency and dialysis-related factors contribute to the impaired immune function that characterizes CKD.

The aim of this review is to summarize the main causes and mechanisms leading to immune dysfunction in CKD.

\section{INNATE IMMUNITY}

The innate immune system is responsible for a rapid and nonspecific inflammatory response to tissue injury and infection. It involves the recognition of specific pathogen-associated molecular patterns (PAMPs) by receptors expressed on effector cells of the innate immune system, such as dendritic cells, macrophages, monocytes, neutrophils, and epithelial cells. Once activated, these effector cells are triggered to perform their functions, including phagocytosis, induction of inflammatory response and presentation of antigens ${ }^{6}$.

Pattern-recognition receptors are divided into three classes and all of them are affected in ESRD:

- Secreted pattern-recognition receptors: this class is represented by mannose-binding lectin (MBL) family. These molecules bind to microbial cell walls and function as opsonins, allowing microbial recognition by the complement system and phagocytes. MBL levels are significantly elevated in patients on $\mathrm{HD}^{7}$, and this seems to have prognostic importance since high levels during the pretransplantation period are associated with worse patient and graft survival on patients undergoing kidney-pancreas transplantation $^{8}$. However, another study showed that low levels of MBL are associated with increased all-cause mortality in HD patients ${ }^{9}$.

- Endocytic pattern-recognition receptors: localized on the surface of phagocytes, they are responsible for the uptake of pathogens into lysosomes. In ESRD patients, two major macrophage scavenger receptors, SR-A and CD36, are increased, which may represent a chronic stimulation of these receptors in an environment of inflammation and oxidative stress ${ }^{10,11}$. 
- Signaling pattern-recognition receptors: represented by the Toll-like receptor (TLR) family, these receptors recognize multiple pathogenic components and mediate the activation of numerous cytokines and the complement pathway ${ }^{12,13}$. They also have a role in the maturation of dendritic cells - antigen-presenting cells (APCs) - by upregulating the expression of the costimulatory molecules CD80 and $C D 86^{14}$. Uremia is known to impair the antigen presentation capabilities of APCs and it seems to be caused by defects in TLR expression. In fact, TLR4 expression was found to be diminished in predialysis patients, mainly those predisposed to bacterial infections, and it is associated with reduced synthesis of cytokines in response to LPS stimulation ${ }^{15}$. Comparable results were found in HD patients, leading to the hypothesis that endotoxins contained in the dialysate may suppress TLR4 expression ${ }^{16}$.

In ESRD patients, there is spontaneous activation of monocytes, mainly of the CD14+CD16+ subset, which have a particularly high capacity to produce inflammatory cytokines and contribute to the oxidative stress and systemic inflammation that prevail in $\mathrm{CKD}^{17}$. In addition, the monocyte's phagocytic capacity is also impaired, contributing to the increased susceptibility to infection of this population ${ }^{18}$.

Polymorphonuclear leucocytes' phagocytic capacity is also compromised. Anding et al reported that the bactericidal function of neutrophils in HD patients was inferior to those in the control group ${ }^{19}$. Moreover, it is also known that uremic solutes modulate neutrophils' apoptosis. Many studies showed accelerated apoptosis of normal neutrophils in the serum of ESRD patients ${ }^{20,21}$. Enhanced apoptosis reduces the response against infections; however removal of activated immune cells is also important to ameliorate the inflammatory state of ESRD 22,23 .

\section{ADAPTIVE IMMUNITY}

The adaptive immune system is responsible for an antigen-specific response and involves production of antibodies and a memory of immune responses that enables long-term protection to the host. $T$ and $B$ lymphocytes are the main agents of adaptive immunity ${ }^{24}$.

ESRD patients' increased risk of infection, impaired response to vaccination and higher anergy rates to delayed-type hypersensitivity skin tests (e.g. tuberculin test) suggest a deficient adaptive immunity 25 .

In vitro studies have shown decreased T-cell proliferation in the uremic milieu ${ }^{26,27}$. ESRD patients were found to have significantly depleted naïve and central memory CD4+ and CD8+ T-cells and a reduced $\mathrm{CD} 4+/ \mathrm{CD} 8+$ ratio. Also, a negative correlation was found between the number of naive T-cells and severity of azotemia, hyperphosphatemia and oxidative stress ${ }^{28}$. This finding may be due to increased susceptibility of these cells to apoptosis, as was shown in multiple studies ${ }^{29-31}$. In fact, Meier et al showed that activated T-cells undergo a process of accelerated apoptosis that is more pronounced in HD patients when compared to pre-dialysis patients and healthy controls. This may be explained by the persistent contact between blood and the synthetic HD membrane ${ }^{30}$. Moreover, uremic patients also have a predominance of Th2 over Th1 lymphocytes, which is caused by an increased susceptibility to apoptosis of the latter. Since
Th1 lymphocytes are the principal effectors of cell-mediated immunity, this imbalance may be responsible for the altered cellular immunity seen in uremic patients ${ }^{31,32}$

ESRD is also associated with B-cell lymphopenia, which may be mediated by increased apoptosis and impaired differentiation and maturation of transitional B-cells, through resistance to the biological actions of B-Cell Activating Factor of tumor necrosis family (BAFF) 33,34 .

Impaired innate and adaptive immunity determines the poor response to vaccination seen in CKD patients. Reduced capacity of dendritic cells to present antigens and changes in T-cell subsets and functions compromise the ability of B-cells to produce long term memory ${ }^{5}$. Litjens et al evaluated the antigen-specific T-cell response after vaccination with hepatitis B surface antigen ( $\mathrm{HBsAg}$ ) of ESRD patients. They concluded that the production of antigen-specific effector memory CD4+ T-cells is severely reduced in ESRD patients, which was strongly associated with low serologic response to $\mathrm{HBsAg}^{35}$. Improving vaccination effectiveness is of upmost importance since ESRD patients, mainly those on HD, are particularly susceptible to infection with hepatitis B virus (HBV) due to increased exposure to blood products. Some studies showed improvement in vaccination response in ESRD patients with immune adjuvants, such as granulocyte macrophage colony stimulating factor (GM-CSF) and levamisole, agents that promote antigen presenting cells' function and maturation. ${ }^{36-39}$ More recently, a CPG-oligodeoxynucleotide adjuvant, which stimulates TLR9, has successfully enhanced hepatitis $B$ antigen-based vaccine seroprotection in CKD patients ${ }^{40}$.

In addition to disturbance of the immune system, there are other factors that contribute to impaired immunity in CKD patients, including intestinal dysbiosis, oxidative stress and inflammation and other CKD complications such as mineral bone disease (MBD) and anemia.

\section{INTESTINAL DYSBIOSIS}

Numerous studies have shown that uremia profoundly alters the gut microbiota, leading to an increase in intestinal pathobions ${ }^{41,42}$. Metabolic acidosis, retention of uremic toxins, volume overload with intestinal congestion, frequent use of antibiotics and iron that promote bacterial overgrowth and dietary restrictions are the main contributors to intestinal dysbiosis in $\mathrm{CKD}^{43}$. Wang et al proved that uremia increases bacterial translocation, which is associated with increased levels of IL- 6 and C-reactive protein, markers of systemic inflammation ${ }^{42}$. Further, the work of McIntyre and colleagues showed increased levels of lipopolysaccharide (LPS), a component of the outer membrane of gram-negative bacteria, in patients on $\mathrm{HD}$ and $P D^{44}$. Thus, uremiarelated dysbiosis may be responsible for the persistent inflammatory state seen in CKD patients.

\section{OXIDATIVE STRESS AND INFLAMMATION}

Oxidative stress presents early during CKD progression and is inversely correlated with $\mathrm{GFR}^{45}$. Increased reactive oxygen species in CKD are attributable to retention of uremic solutes and increased production of cytokines, as well as antioxidant depletion ${ }^{46}$. In spite 
of being critical for the response against infection, it may cause deleterious effects, such as hypertension, endothelial dysfunction, atherosclerosis and inflammation if not properly regulated.

\section{ERYTHROPOIETIN AND IRON}

Erythropoietin (EPO) is a hormone secreted by the kidney in response to cellular hypoxia in order to stimulate the production of red blood cells in the bone marrow. CKD patients have lower levels of EPO when compared to healthy subjects and are consequently treated with recombinant human EPO. Iron deficiency, infection and proinflammatory cytokines such as IL-1, TNF- $\alpha$ and interferon- $\gamma$ play a major role in causing a poor response to this therapy ${ }^{47}$. In order to achieve increased responsiveness to erythropoiesis-stimulating agents, the majority of CKD patients need iron supplementation. However, iron therapy is associated with depressed polymorphonuclear killing capacity and it also affects $T$ and B lymphocytes ${ }^{48,49}$.

\section{MINERAL BONE DISEASE}

Vitamin D deficiency is a very prevalent finding in CKD patients. Traditionally, it has been associated with hyperparathyroidism and mineral bone disease; however, studies have demonstrated its pleiotropic effects, which include modulation of the immune system, regulation of inflammatory responses and suppression of the renin-angiotensin system, among others ${ }^{50,51}$. In fact, vitamin D repletion was linked to a decreased Th1 mediated autoimmune diseases and an increased bactericidal activity ${ }^{52}$.

High levels of cytosolic calcium of polymorphonuclear leucocytes were found in HD patients, which were associated with decreased reactivity upon stimulation and consequently dysfunction ${ }^{53}$. This sustained elevation of cytosolic calcium appears to be due to the effects of parathyroid hormone (PTH), the levels of which are increased in CKD patients, and may be prevented by calcium channel blockers ${ }^{53,54}$. Hyperparathyroidism also adversely affects the function of $T$ and $B$ lymphocytes, leading to impaired cellular and humoral immunity 55 .

\section{RENIN-ANGIOTENSIN SYSTEM}

In addition to its pathogenic role in the regulation of blood pressure and the progression of CKD and cardiovascular diseases, angiotensin-II also has a major role in regulating inflammation. It is involved in cell proliferation and chemotaxis, as well as recruitment of proinflammatory cells to the site of injury ${ }^{56,57}$. It was also demonstrated that inflammatory cells such as T-cells, NK-cells and monocytes contain renin-angiotensin system elements, suggesting that they are able to produce and deliver angiotensin-II to the damaged tissue, perpetuating the inflammatory process 58 .

\section{CONCLUSION}

Uremia is associated with a state of both immune dysfunction (which affects the innate and adaptive system and is characterized with increased prevalence of infections), and immunoactivation caused by a persistent and systemic inflammatory state. This abnormality in the immune system seems to contribute to the cardiovascular and infectious complications that constitute the most common causes of death among CKD patients.

Disclosure of potential conflicts of interest: none declared.

\section{References}

1. Eckardt K. et al. Evolving importance of kidney disease: from subspecialty to global health burden. Lancet 2013; 382(9887):158-69.

2. Go AS, Chertow GM, Fan D, McCulloch CE, Hsu C. Chronic kidney disease and the risks of death, cardiovascular events, and hospitalization. N Engl J Med 2004; 351(13):1296-305.

3. Powe NR, Jaar B, Furth SL, Hermann J, Briggs W. Septicemia in dialysis patients: Incidence, risk factors, and prognosis. Kidney Int 1999; 55(3):1081-1090.

4. Sarnak MJ, Jaber BL. Mortality caused by sepsis in patients with end-stage renal disease compared with the general population. Kidney Int 2000; 58(4):1758-1764.

5. Pesanti EL. Immunologic defects and vaccination in patients with chronic renal failure. Infect Dis Clin North Am 2001; 15(3):813-832.

6. Kato S. et al. Aspects of Immune Dysfunction in End-stage Renal Disease. Clin J Am Soc Nephrol 2008; 3(5);1526-1533.

7. Satomura A. et al. Significant Elevations in Serum Mannose-Binding Lectin Levels in Patients with Chronic Renal Failure. Nephron 2002; 92(3):702-704.

8. Berger SP, Roos A, Mallat MJK, Schaapherder AFM, de Fijter JW, Daha MR. Low Pretransplantation Mannose-Binding Lectin Levels Predict Superior Patient and Graft Survival after Simultaneous Pancreas-Kidney Transplantation. J Am Soc Nephrol 2007; 18(8):2416-2422.

9. Satomura A, Ohi H. Serum Mannose-Binding Lectin Levels in Maintenance Hemodialysis Patients: Impact on All-Cause Mortality. Nephron Clin Pr 2006; 102(3-4):93-99.

10. Ando $M$, Gafvels $M$, Bergstrom J, Lindholm B, Lundkvist I. Uremic serum enhances scavenger receptor expression and activity in the human monocytic cell line U937. Kidney Int 1997; 51(3):785-792.

11. Ando M, Lundkvist I, Bergstrom J, Lindholm B. Enhanced scavenger receptor expression in monocyte-macrophages in dialysis patients. Kidney Int 1996; 49(3):773-780.

12. Pasare C, Medzhitov R. Toll-like receptors: linking innate and adaptive immunity. Microbes Infect 2004; 6(15):1382-1387.

13. De Nardo D. Cytokine Toll-like receptors: Activation, signalling and transcriptional modulation. Cytokine 2015; 74(2):181-189.

14. Girndt M, Sester M, Sester U, Kaul H, Kohler H. Defective expression of B7-2 (CD86) on monocytes of dialysis patients correlates to the uremia-associated immune defect. Kidney Int 2001; 59(4):1382-1389.

15. Ando M, Shibuya A, Tsuchiya K, Akiba T, Nitta K. Reduced expression of Toll-like receptor 4 contributes to impaired cytokine response of monocytes in uremic patients. Kidney Int 2006; 70(2);358-362.

16. Kuroki Y. et al. A study of innate immunity in patients with end-stage renal disease: Special reference to toll-like receptor-2 and -4 expression in peripheral blood monocytes of hemodialysis patients. Int J Mol Med 2007; 19(5):783-790.

17. Gollapudi P, Yoon JW, Gollapudi S, PahI MV, Vaziri ND. Leukocyte Toll-Like Receptor Expression in End-Stage Kidney Disease. Am J Nephrol 2010; 31(3):247-254.

18. Alexiewicz J, Smogorzewski M, Fadda GZ, Massry S. Impaired Phagocytosis in Dialysis Patient: Studies on Mechanisms. Am J Nephrol 1991; 11(2):102-111.

19. Anding K, Gross P, Rost JM, Allgaier D, Jacobs E. The influence of uraemia and haemodialysis on neutrophil phagocytosis and antimicrobial killing. Nephrol Dial Transpl 2003; 18(10):2067-2073.

20. Cendoroglo M. et al. Neutrophil Apoptosis and Dysfunction in Uremia. J Am Soc Nephrol 1999; 10(1):93-100.

21. Sela S. et al. Primed Peripheral Polymorphonuclear Leukocyte: A Culprit Underlying Chronic LowGrade Inflammation and Systemic Oxidative Stress in Chronic Kidney Disease. J Am Soc Nephrol 2005; 16(8):2431-2439.

22. Glorieux $G$, Vanholder R, Lameire N. Uraemic retention and apoptosis: what is the balance for the inflammatory status in uraemia? Eur J Clin Invest 2003; 33(8):631-634.

23. Cohen G, Hörl WH. Immune Dysfunction in Uremia-An Update. Toxins 2012; 4(11):962-990.

24. Delves PJ, Roitt IM. The Immune System. N Engl J Med 2000; 343(1):37-49.

25. Eleftheriadis T, Antoniadi G, Liakopoulos V, Kartsios C, Stefanidis I. Disturbances of Acquired Immunity in Hemodialysis Patients. Semin Dial 2007; 20(5):440-451.

26. Stachowski J, Pollok M, Burrichter H, Spithaler C, Baldamus CA. Signalling via the TCR/CD3 Antigen Receptor Complex in Uremia is Limited by the Receptors Number. Nephron 1993; 64(3):369-375.

27. Kurz P, Buschenfelde KM, Khlert H, Meuer SC. Selective Blockade of the Antigen-ReceptorMediated Pathway of T Cell Activation in Patients with Impaired Primary Immune Responses. J Clin Invest 1987; 80(3):743-749.

28. Yoon J, Gollapudi S, Pahl MV, Vaziri ND. Naive and central memory T-cell lymphopenia in end-stage renal disease. Kidney Int 2006; 70(2):371-376.

29. Matsumoto Y. et al. Relationship between Susceptibility to Apoptosis and Fas Expression in Peripheral Blood T Cells from Uremic Patients: A Possible Mechanism for Lymphopenia in Chronic Renal Failure. Biochem Biophys Res Commun 1995; 215(1):96-105. 
30. Meier P, Dayer E, Blanc E. Early T Cell Activation Correlates with Expression of Apoptosis Markers in Patients with End-Stage Renal Disease. J Am Soc Nephrol 2002; 13(1):204-212.

31. Moser B. et al. Aberrant T cell activation and heightened apoptotic turnover in end-stage renal failure patients: a comparative evaluation between non-dialysis, haemodialysis, and peritoneal dialysis. Biochem Biophys Res Commun 2003; 308(3): 581-585.

32. Alvarez-Lara MA. et al. The imbalance in the ratio of Th1 and Th2 helper lymphocytes in uraemia is mediated by an increased apoptosis of Th1 subset. Nephrol Dial Transpl 2004; 19(12):3084-3090.

33. Fernández-Fresnedo G. et al. B lymphopenia in uraemia is related to an accelerated in vitro apoptosis and dysregulation of Bcl-2. Nephrol Dial Transpl 2000; 15(4):502-510.

34. Pahl MV. et al. Effect of end-stage renal disease on B-lymphocyte subpopulations, IL-7, BAFF and BAFF receptor expression. Nephrol Dial Transpl 2010; 25(1):205-12.

35. Litjens NHR, Huisman M, van den Dorpel M, Betjes MGH. Impaired Immune Responses and Antigen-Specific Memory CD4+ T Cells in Hemodialysis Patients. J Am Soc Nephrol 2008; 19(8):1483-1490.

36. Verkade MA. et al. Peripheral blood dendritic cells and GM-CSF as an adjuvant for hepatitis B vaccination in hemodialysis patients. Kidney Int 2004; 66(2):614-621.

37. Fabrizi F, Ganeshan SV, Dixit V, Martin P. Meta-analysis: the adjuvant role of granulocyte macrophage- colony stimulating factor on immunological response to hepatitis $B$ virus vaccine in endstage renal disease. Aliment Pharmacol Ther 2006; 24(5):789-796.

38. Alavian S, Tabatabaei S. Effects of Oral Levamisole as an Adjuvant to Hepatitis B Vaccine in Adults With End-Stage Renal Disease: A Meta-Analysis of Controlled Clinical Trials. Clin Ther 2010; 32(1):1-10.

39. Fabrizi F, Dixit V, Messa P, Martin P. Alimentary Pharmacology and Therapeutics Meta-analysis: levamisole improves the immune response to hepatitis $B$ vaccine in dialysis patients. Aliment Pharmacol Ther 2010; 32(6):756-62.

40. Halperin SA. et al. Immunogenicity of an investigational hepatitis B vaccine (hepatitis B surface antigen co-administered with an immunostimulatory phosphorothioate oligodeoxyribonucleotide) in nonresponders to licensed hepatitis B vaccine. Hum Vaccin Immunother 2013; 9(7):1438-1444.

41. Vaziri ND. et al. Chronic kidney disease alters intestinal microbial flora. Kidney Int 2013; 83(2):308315.

42. Wang F, Zhang P, Jiang H, Cheng S. Gut Bacterial Translocation Contributes to Microinflammation in Experimental Uremia. Dig Dis Sci 2012; 57(11):2856-2862.

43. Anders $\mathrm{HJ}$, Andersen K, Stecher B. The intestinal microbiota, a leaky gut, and abnormal immunity in kidney disease. Kidney Int 2013; 83(6):1010-1016.

44. Mcintyre CW. et al. Circulating Endotoxemia: A Novel Factor in Systemic Kidney Disease. Clin J Am Soc Nephrol 2011; 6(1):133-141.

45. Dounousi E. et al. Oxidative Stress is Progressively Enhanced with Advancing Stages of CKD. Am J Kidney Dis 2006; 48(5):752-760.

46. Pecoits-Filho R. et al. Associations Between Circulating Inflammatory Markers and Residual Renal Function in CRF Patients. Am J Kidney Dis 2003; 41(6):1212-1218.
47. Macdougall IC, Cooper AC. Erythropoietin resistance: the role of inflammation and pro-inflammatory cytokines. Nephrol Dial Transpl 2002; 17(Suppl 11):39-43.

48. Deicher R, Ziai F, Cohen G, Mullner M, Horl WH. High-dose parenteral iron sucrose depresses neutrophil intracellular killing capacity. Kidney Int 2003; 64(2):728-736.

49. Patruta SI, Horl WH. Iron and infection. Kidney Int 1999; 69(1)125-130.

50. Shroff R, Wan M, Rees L. Can vitamin D slow down the progression of chronic kidney disease? Pediatr Nephrol 2012; 27(12):2167-2173.

51. Jorge C. Vitamin D - new insights into an old molecule. Port J Nephrol Hypert 2019; 33(3):155-162.

52. Cantorna MT, Yu S, Bruce D. The paradoxical effects of vitamin D on type 1 mediated immunity. Mol Aspects Med 2008; 29(6):369-375.

53. Horl WH, Haag-Weber M, Mai B, Massry SG. Verapamil reverses abnormal [Ca2+]i and carbohydrate metabolism of PMNL of dialysis patients. Kidney Int 1995; 47(6):1741-1745.

54. Massry SG,Smogorzewski M. Dysfunction of polymorphonuclear leukocytes in uremia: role of parathyroid hormone. Kidney Int 2001; 78:S195-S196.

55. Smogorzewski M, Massry SG. Defects in B-cell function and metabolism in uremia: Role of parathyroid hormone. Kidney Int 2001; 78:S186-S189.

56. Ruiz-Ortega M, Lorenzo O, Suzuki Y, Rupérez M, Egido J. Proinflammatory actions of angiotensins. Curr Opin Nephrol Hypertens 2001; 10(3):321-329.

57. Suzuki Y. et al. Susceptibility to T Cell-Mediated Injury in Immune Complex Disease Is Linked to Local Activation of Renin-Angiotensin System: The Role of NF-AT Pathway. J Immunol 2002; 169(8):4136-4146.

58. Jurewicz M. et al. Human T and Natural Killer Cells Possess a Functional Renin-Angiotensin System: Further Mechanisms of Angiotensin II - Induced Inflammation. J Am Soc Nephrol 2007; 18(4):1093-1102.

\section{ORCID}

Sara Cardoso Fernandes (iD 0000-0003-2224-2601

Ana Carina Ferreira (iD) 0000-0002-1323-5293

\section{Correspondence to:}

Sara Cardoso Fernandes, MD

Nephrology Department, Hospital Curry Cabral

Centro Hospitalar Universitário Lisboa Central, Lisbon, Portugal

E-mail: saracardfernandes@gmail.com 